\title{
Announcement
}

\section{The 2020 Albert Valdman Award}

We are pleased to announce that the winner of the Albert Valdman Award for outstanding publication in 2020 is:

"Predicting language proficiency in bilingual children" by Cécile De Cat

Please join us in congratulating this author on her contribution to the journal and to the field.

A note from this year's winner:

I would like to express my deep gratitude to the review board at SSLA for selecting my paper ("Predicting proficiency in bilingual children", April 2020) for the Albert Valdman 2020 outstanding publication award. This double-length article reports on a multifaceted investigation of the environmental and cognitive predictors of proficiency in English as the school language, in a diverse group of 5- to 7-year-old heritage speakers of a variety of other languages. It adopts a data-driven approach to compare the informativity of alternative predictors (e.g., current vs. cumulative language exposure) and to identify thresholds in exposure beyond which bilinguals are likely to perform within the monolingual range across language domains. These questions are relevant to researchers and practitioners, irrespective of theoretical persuasion. The data and code are openly available via the Open Science Framework, in the hope that others will respond to the invitation to explore some of the outstanding questions in other populations of bilingual children, and with respect to the heritage language.

\section{REFERENCE}

De Cat, C. (2020). Predicting language proficiency in bilingual children. Studies in Second Language Acquisition, 42, 279-325. 